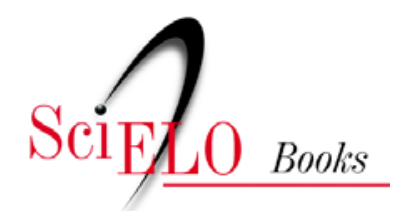

\title{
Capítulo 8 - Relatando a experiência com a Comunicação Alternativa e Ampliada a partir da participação em curso de formação continuada para professores de Salas de Recursos
}

\author{
Gabriela Ferreira Ramiro de Souza \\ Carolina Rizzotto Schirmer
}

\section{SciELO Books / SciELO Livros / SciELO Libros}

SOUZA, G. F. R., and SCHIRMER, C. R. Relatando a experiência com a Comunicação Alternativa e Ampliada a partir da participação em curso de formação continuada para professores de Salas de Recursos. In: NUNES, L. R. O. P., and SCHIRMER, C. R., orgs. Salas abertas: formação de professores e práticas pedagógicas em comunicação alternativa e ampliada nas salas de recurso multifuncionais [online]. Rio de Janeiro: EDUERJ, 2017, pp. 177-182. ISBN: 978-85-7511-452-0. Available from: doi: 10.7476/9788575114520.010. Also available in ePUB from: http://books.scielo.org/id/xns62/epub/nunes-9788575114520.epub.

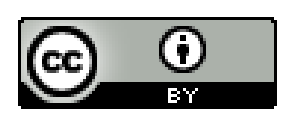

All the contents of this work, except where otherwise noted, is licensed under a Creative Commons Attribution 4.0 International license.

Todo o conteúdo deste trabalho, exceto quando houver ressalva, é publicado sob a licença Creative Commons Atribição 4.0.

Todo el contenido de esta obra, excepto donde se indique lo contrario, está bajo licencia de la licencia $\underline{\text { Creative Commons }}$ $\underline{\text { Reconocimento 4.0. }}$ 


\section{Capítulo 8 - Relatando a experiência com a Comunicação Alternativa e Ampliada a partir da participação em curso de formação continuada para professores de Salas de Recursos}

Gabriela Ferreira Ramiro de Souza Carolina Rizzotto Schirmer ${ }^{2}$

\section{Introdução}

Como professora de Sala de Recursos Multifuncionais (SRM) da Rede Municipal de Educação do Rio de Janeiro, e após uma experiência de seis anos, fui incentivada pela coordenadora da equipe de Educação Especial da CRE a participar, em 2013, do curso de Formação Continuada em Serviço, oferecido pela Universidade do Estado do Rio de Janeiro (UERJ) em parceria com a Oficina Vivencial (OV) do Instituto Municipal Helena Antipoff (IHA). Essa pesquisa foi aprovada pelo Co-

1 Secretaria Municipal de Educação do Rio de Janeiro. E-mail: ofvivencialiha@rio.rj.gov. br

2 Professora adjunta da Faculdade de Educação da UERJ. E-mail: ead.carolina@gmail. com 
mitê de Ética (Proc. 336.622, de 11/07/2013, do COEP/UERJ) e financiada pela FAPERJ e pelo CNPq. A formação, que ocorreu de maio de 2013 a dezembro de 2016, possibilitou-me o contato com discussões e a troca de vivências sobre questôes inquietantes a respeito do desenvolvimento dos alunos com deficiência e TEA.

As SRMs acompanham um diversificado grupo de alunos, abrangendo pessoas com deficiência, transtornos globais de desenvolvimento $(\mathrm{TGD})^{3}$ e altas habilidades/superdotação (AH/SD) (MEC, 2008). Para atuar no Atendimento Educacional Especializado (AEE), o professor precisa estar disposto a enfrentar os desafios de trabalhar com uma variedade de especificidades dentro de grupos com a mesma classificação, o que se torna possível quando o profissional adquire conhecimentos teóricos e práticos para dar conta de qualquer tipo de deficiência ou transtorno que façam parte desse público alvo (Pletsch, 2009).

Este capítulo tem por objetivo descrever a experiência que tive como participante da pesquisa e contar as mudanças ocorridas na minha prática pedagógica, bem como na postura pessoal diante das situaçôes cotidianas dos alunos com necessidades educacionais especiais e das especificidades de cada um. E isso modificou também a minha atuação como professora e a maneira como observo o desenvolvimento dos alunos que são acompanhados em SRMs.

\section{Metodologia}

Durante o curso de formação continuada, houve palestras ministradas por especialistas na área da Educação Especial, tais como Eduardo Manzini, Cátia Walter, Débora Deliberato, Leila Nunes e Carolina Schirmer, que dividiram com o grupo de professoras parte da vasta experiência que possuem nas áreas de Linguagem, Interação e Comunicação Aternativa e Ampliada (CAA), PECS-Adaptado, currículo funcional, políticas públicas, entre outros temas.

3 Atualmente, Transtornos do Espectro Autista (TEA) 
Em outro momento, durante a formação, foram utilizadas filmagens realizadas a partir do registro em vídeo das práticas pedagógicas vivenciadas pelos professores participantes do curso, bem como do cotidiano escolar de seus respectivos alunos. Essas filmagens serviram de base para o debate e para a construção de conhecimento. O estudo em grupo desse material possibilitou a criação de estratégias pontuais na busca por minimizar as barreiras do desenvolvimento dos alunos com deficiência e TEA, trazendo consequências benéficas para a vida do aluno não só na escola, como também fora do ambiente escolar. $\mathrm{O}$ ato de observar meu desempenho junto ao aluno propiciou mudanças em velhos hábitos antes imperceptíveis aos meus olhos, como, por exemplo, a aflição durante a espera da resposta do discente, quando, por precipitação, acabava por responder às minhas próprias perguntas sem dar tempo a ele. Depois que percebi essa dificuldade, passei a respeitar o tempo necessário do aluno. Por vezes, nas gravaçôes, pedia calma a ele quando, na realidade, o pedido era para mim mesma, buscando diminuir minha aflição.

No ano de 2014, ocorreu um desdobramento na pesquisa. Os vídeos da atuação da professora com seu aluno eram enviados para a pesquisadora Thatyana Machado Silva, que destacava trechos do vídeo a fim de direcionar a intencionalidade da prática do professor e estimular a autorreflexão deste ao confrontar suas ações com o objetivo proposto, bem como avaliar o desempenho de seu aluno. Essa prática é denominada de autoscopia (Sadalla e Larocca, 2004). A ação proporciona a troca de experiências a partir da observação das ações pedagógicas dos outros participantes, fomentando a criação de hipóteses e sugestôes com a intenção de melhorar as práticas cotidianas dos atendimentos.

$\mathrm{Na}$ busca por possíveis benefícios da utilização da CAA, foram selecionados casos de alunos sem fala funcional como participantes específicos da pesquisa para o estudo em formação. O caso acompanhado foi de um aluno com TEA que apresentava uma fala sem funcionalidade e não realizava trocas comunicativas. Respondia a tudo por meio da ecolalia, o que gerava dúvidas sobre se realmente desejava algo ou se era apenas uma reprodução do que ouvia. Após alguns anos acompanhando o desenvolvimento desse aluno, percebo o quanto a CAA ajudou na organização do pensamento e facilitou a expressão oral das informações 
que desejava transmitir, o que desmistificou a falsa impressão de que a utilização da CAA pudesse inibir a fala, sendo essa uma das primeiras dúvidas levantadas pela família. Vivenciar esse processo me tornou mais segura para a utilização com outras crianças.

Figura 1 - Aluno utilizando cartões de CAA no contexto da Sala de Recursos Multifuncionais

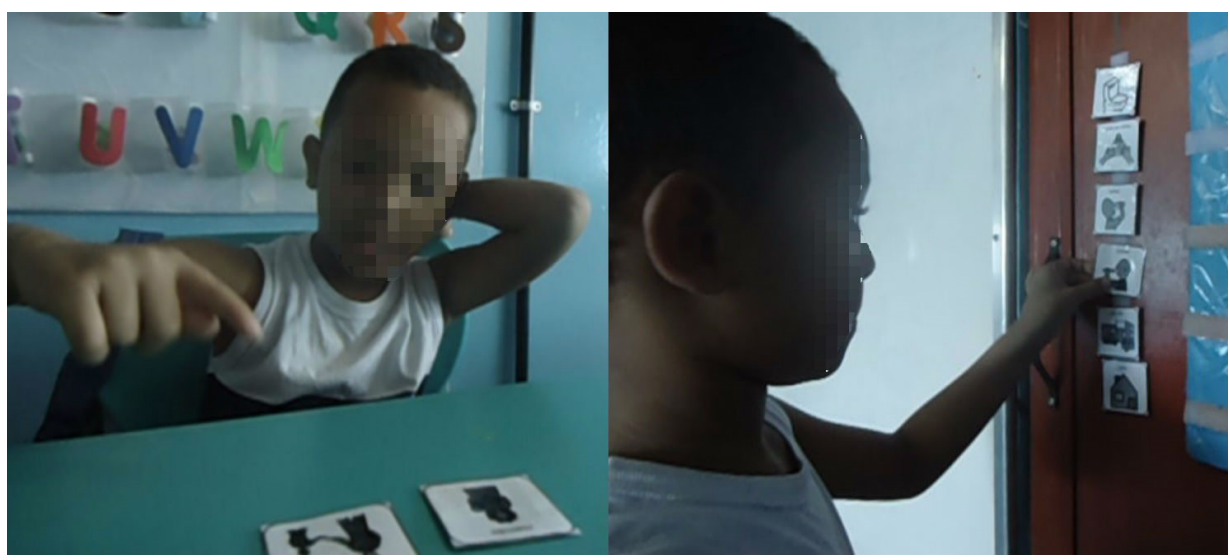

Fonte: G. R. F. Souza.

\section{Resultado}

O contato com a CAA ocorreu durante alguns anos de trabalho com Educação Especial, mas somente após a experiência do acompanhamento dos vídeos propostos pelo curso de formação superei minha insegurança ao implementar o uso da CAA, fortalecendo a sua utilização e desmistificando alguns medos, como: a incerteza de não ter todo o arsenal de vocabulário necessário para que uma criança sem fala comunique-se e a ideia de que o uso da CAA por crianças com fala, mas sem intenção comunicativa, possa inibir sua expressão oral.

$\mathrm{O}$ estudo gerou o meu empoderamento, distanciando a ideia de certo ou errado, uma vez que não há modelos prontos estabelecidas para 
todas as situações, muitas vezes novas, e somente por meio das tentativas pode-se encontrar um caminho. Para que a comunicação possa acontecer, é necessário que o professor coloque-se à disposição do aluno. Não basta usar o melhor recurso, o mais importante é permitir que o professor seja um mediador entre o aluno e esse recurso.

Com os resultados observados por mim na comparação entre duas crianças atendidas na SRM, utilizando a CAA, ficou evidente a importância da família na utilização dos cartôes de comunicação. Uma das crianças que passou a utilizar os cartões em sua casa, apropriou-se rapidamente deles, enquanto a outra criança, cuja família não colaborou para o uso efetivo da CAA, precisou ser lembrada como se estivesse sendo apresentada aos recursos pela primeira vez.

Como benefício da autoscopia para a prática pedagógica, percebo que professores que têm a oportunidade de receber a formação de acordo com os conflitos emergentes do cotidiano conseguem planejar, executar, autoavaliar-se e promover mudanças para alcançar os objetivos. Somente por meio da visualização de nossa prática podemos descobrir por que, mesmo quando temos um planejamento que parece estar perfeitamente adequado à necessidade do aluno, ainda assim não é possível dar conta das situações cotidianas. Portanto, a reflexão que os professores realizam favorece a criação de estratégias para melhorar o seu desempenho como docentes de Sala de Recursos.

\section{Conclusões}

As mudanças profissional e pessoal que o curso ofereceu são imensuráveis. Além de encorajar e proporcionar trocas riquíssimas, o trabalho de autorreflexão da autoscopia foi ótimo para o autoconhecimento. O olhar para mim mesma, o permitir-me ser avaliada e repensar as minhas próprias ações pedagógicas fizeram com que eu, professora e profissional, me conhecesse melhor. Agora, um ser humano capaz de ouvir críticas e de crescer com os erros. Lições como esperar o tempo do aluno só puderam ser observadas após as análises dos vídeos. Algumas açōes, como o pedido de compreensão por parte do discente, eram, na realidade, clara- 
mente um pedido de calma a mim mesma. A aflição da necessidade de um retorno rápido atropelava o momento do aluno. 